\title{
PRODUÇÃO DE MUDAS DE RÚCULA EM BANDEJAS COM SUBSTRATOS A BASE DE RESÍDUOS ORGÂNICOS
}

\author{
Production of rocket (Eruca sativa) seedlings with substrates composed of organic waste
}

\author{
Lya Januária Beiruth da Silva ${ }^{1}$, Ana Suzette da Silva Cavalcante ${ }^{2}$, Sebastião Elviro de Araújo Neto ${ }^{3}$
}

\begin{abstract}
RESUMO
Com o objetivo de avaliar o efeito de diferentes substratos na produção de biomassa vegetal em mudas de rúcula, cv. cultivada, foi conduzido um experimento na Universidade Federal do Acre, no período de setembro a novembro de 2006, utilizando os seguintes tratamentos: $\mathrm{T}_{1}$ - Plantmax ${ }^{\circledR}$ (Tratamento padrão); $\mathrm{T}_{2}$ - composto orgânico $(\mathrm{CO})+$ casca de coco maduro triturado $(\mathrm{CCMT})(1: 1 \mathrm{v} / \mathrm{v})$; $\mathrm{T}_{3}-\mathrm{CO}+$ cama de aviário $(\mathrm{CA})+$ casca-de-arroz carbonizada $(\mathrm{CAC})(1: 1: 1 \mathrm{v} / \mathrm{v}) ; \mathrm{T}_{4}-\mathrm{CO}+$ esterco bovino $(\mathrm{EB})+\mathrm{CAC}(1: 1: 1 \mathrm{v} / \mathrm{v}) ; \mathrm{T}_{5}$ - CO + coprólitos de minhoca $(\mathrm{CM})+\mathrm{CAC}(1: 1: 1 \mathrm{v} / \mathrm{v}) ; \mathrm{T}_{6}-\mathrm{CO}+\mathrm{CM}+$ caroço de açaí triturado (CAT) $(1: 1: 1 \mathrm{v} / \mathrm{v}) ; \mathrm{T}_{7}-\mathrm{CO}+\mathrm{CM}+$ CCMT (1:1:1 v/v); $\mathrm{T}_{8}-\mathrm{CO}+\mathrm{EB}+\mathrm{CCMT}(1: 1: 1 \mathrm{v} / \mathrm{v})$. Foram acrescidos, $10 \%$ de carvão vegetal triturado, $1,0 \mathrm{~kg} \mathrm{~m}^{-3}$ de calcário dolomitico e $1,5 \mathrm{~kg} \mathrm{~m}^{-3}$ de termofosfato, exceto no substrato $\mathrm{T}_{1}$. A semeadura foi feita utilizando-se três sementes por células em bandejas de poliestireno expandido, contendo os diferentes tratamentos e oito dias após a semeadura, foi feito o desbaste deixando-se apenas uma planta por célula. Aos 26 dias após a semeadura, foram avaliados a massa da matéria fresca da parte aérea, massa da matéria seca da parte aérea, raiz e total da planta. O delineamento experimental foi inteiramente casualizado, com três repetições, sendo cada unidade experimental constituída de 4 plantas. Os tratamentos $\mathrm{T}_{4}, \mathrm{~T}_{5}$ e $\mathrm{T}_{7}$ foram os que promoveram maior massa fresca e seca das plantas e não diferiram estatisticamente entre si e do tratamento padrão $\left(\mathrm{T}_{1}\right)$, para todas as características avaliados.
\end{abstract}

Termos para indexação: Eruca sativa, propagação, adubo orgânico, casca-de-coco.

\begin{abstract}
With the objective of evaluating the effect of different substrates in the production of vegetable biomass on rocket (Eruca sativa) seedlings cv. cultivated, an experiment was carried out at the Federal University of Acre, in the period from September to November of 2006, using the following treatments: $\mathrm{T}_{1}-$ Plantmax ${ }^{\circledR}$ (control), $\mathrm{T}_{2}$ - organic compost + triturated ripe coconut shells $(1: 1 \mathrm{v} / \mathrm{v}), \mathrm{T}_{3}-$ organic compost + poultry litter + carbonized rice hulls $(1: 1: 1 \mathrm{v} / \mathrm{v}), \mathrm{T}_{4}-$ organic compost + bovine manure + carbonized rice hulls $(1: 1: 1 \mathrm{v} / \mathrm{v}), \mathrm{T}_{5}-$ organic compost + earthworm casting + carbonized rice hulls $(1: 1: 1 \mathrm{v} / \mathrm{v}), \mathrm{T}_{6}-$ organic compost + earthworm casting + triturated açaí pit $(1: 1: 1 \mathrm{v} / \mathrm{v}), \mathrm{T}_{7}$ - organic compost + earthworm casting + triturated ripe coconut shells $(1: 1: 1$ $\mathrm{v} / \mathrm{v})$ e $\mathrm{T}_{8}$ - organic compost + bovine manure + triturated ripe coconut shells $(1: 1: 1 \mathrm{v} / \mathrm{v})$. Ten percent triturated charcoal, $1.0 \mathrm{~kg} . \mathrm{m}^{-3}$ of lime and $1.5 \mathrm{~kg} \cdot \mathrm{m}^{-3}$ of thermophosphate were added, except in $\mathrm{T}_{1}$ treatment. The sowing was done using three seeds per cell in expanded polystyrene trays containing the different substrates. Eight days after sowing, thinning was done leaving just 1 plant per cell. On the 26th day after sowing, the fresh mass of the aerial part, the dry mass of the aerial part, root, and the whole plant were appraised. The experimental design was entirely randomized with 8 treatments and 3 repetitions, and with 4 plants per plot. Treatments $\mathrm{T}_{4}, \mathrm{~T}_{5}$ and $\mathrm{T}_{7}$ were the ones that promoted a higher yield of fresh and dry plant mass, and did not differ statistically among themselves, nor from the control treatment $\left(\mathrm{T}_{1}\right)$, for all the characteristics evaluated.
\end{abstract}

Index terms: Eruca sativa, propagation, organic fertilizer, coconut shells.

(Recebido em 1 de outubro de 2007 e aprovado em 6 de fevereiro de 2009)

\section{INTRODUÇÃO}

A rúcula (Eruca sativa Garsault), também denominada pinchão, é pertencente à família Brassicaceae e procedente de áreas do Mediterrâneo e da Ásia Ocidental. Produz folhas muito apreciadas na forma de salada, sendo a mais rica em ferro dentre as demais hortaliças. A cultivar usualmente plantada é a cultivada, que produz plantas vigorosas, com folhas alongadas e de limbo profundamente recortado, de coloração verde-escura e sabor picante (Filgueira, 2003). É uma planta anual, de porte baixo, com folhas relativamente espessas e divididas. Em boas condições culturais e de pleno desenvolvimento, antes de iniciar a formação da haste floral, a planta apresenta-se com altura média de $12 \mathrm{~cm}$ (Filgueira, 2003).

Apesar de produzir melhor sob temperaturas amenas $\left(20\right.$ a $25^{\circ} \mathrm{C}$ ), a rúcula tem sido cultivada ao longo do ano em numerosas regiões do país (Embrapa, 2006).

A produção desta olerácea no Estado do Acre, mesmo sob condições inóspitas para o cultivo, em razão do clima tropical quente e úmido, tem sido intensificada entre os olericultores.

\footnotetext{
${ }^{1} \mathrm{Eng}^{\mathrm{a}}$. Agra . Estudante do Mestrado em Produção Vegetal da UFAC - lyabeiruth24@yahoo.com.br

${ }^{2}$ Eng $^{a}$. Agr ${ }^{a}$. Estudante do Mestrado em Produção Vegetal da UFAC - susyflor@bol.com.br

${ }^{3}$ Eng $^{\circ}$ Agr $^{\circ}$ D. Sc. Fitotecnia, Profo ${ }^{\circ}$. Adjunto da Universidade Federal do Acre - UFAC - Campus, BR364, km04, CEP 69.915-900 - selviro2000@yahoo.com.br
} 
O início da colheita que, em geral, ocorre 40-60 dias após o plantio, sob temperatura elevada, antecipa-se em razão da emissão prematura do pendão floral e, consequentemente, as folhas tornam-se menores e fibrosas, logo, a produção de mudas com substratos de qualidade, torna-se capaz de oferecer um aporte nutricional e, consequentemente, maior produção de biomassa vegetal e poderá favorecer o rendimento desta cultura sobre condições adversas.

Para o bom desenvolvimento de qualquer cultura, é de fundamental importância a utilização de sementes e mudas de boa qualidade. A produção de mudas em canteiros e campo não é prática usual. $\mathrm{O}$ mais usado é a semeadura direta, ou o transplantio de mudas de bandejas. De acordo com Rosas et al. (2002), as sementes ficam em condições bastante desuniformes (solo, chuvas, etc.), consequentemente, a germinação, emergência e crescimento das plântulas também são irregulares, levando a obtenção de estandes falhos e desuniformes.

A produção de mudas constitui-se numa das etapas mais importantes do sistema produtivo hortícola, uma vez que dela depende o desempenho final das plantas nos canteiros de produção, tanto do ponto de vista nutricional, quanto do tempo necessário à produção e, consequentemente, do número de ciclos produtivos possíveis por ano (Filgueira, 2003).

A característica do substrato utilizado na produção de mudas é de fundamental importância no crescimento e desenvolvimento inicial da planta e na definição de seu potencial produtivo. Esse fato se justifica, pois quando se produzem mudas dentro de um recipiente, o crescimento do sistema radicular e a absorção de nutrientes, ao contrário do que ocorre no campo, ficam restritos ao volume do material (substrato) contido no interior do recipiente utilizado. Por essa razão, a condição química do substrato deve ser tal que seja capaz de promover o fornecimento de nutrientes à planta, sem que ocorra deficiência de qualquer elemento essencial a seu crescimento (Moreira, 2005).

Um bom substrato proporciona retenção de água suficiente para germinação, além de permitir a emergência das plântulas, conjuntamente com atributos de boa aeração para permitir a difusão de oxigênio para as raízes, baixa resistência à penetração das raízes e boa resistência à perda de estrutura, além de apresentar disponibilidade de aquisição e transporte, ausência de patógenos, riqueza em nutrientes essenciais, $\mathrm{pH}$ adequado, textura leve-média e estrutura com agregados estáveis (Silva et al., 2001).

O aproveitamento dos resíduos orgânicos disponíveis nas propriedades rurais na produção de mudas, constitui-se numa fonte de nutriente economicamente importante, por reduzir os custos decorrentes da aquisição de adubos químicos para este fim, principalmente se for considerada a posição geográfica do Estado do Acre em relação aos grandes centros produtores de agroquímicos, o que, em razão do transporte, encarece os custos dos insumos agrícolas.

Neste trabalho, objetivou-se avaliar o efeito dos diferentes tipos de substratos à base de resíduos orgânicos na produção de biomassa vegetal em mudas de Rúcula, cv. cultivada.

\section{MATERIALE MÉTODOS}

O experimento foi conduzido em casa-de-vegetação na Universidade Federal do Acre - UFAC, na latitude $9^{\circ} 58^{\prime}$ S e longitude $67^{\circ} 48^{\prime} \mathrm{W}$ e altitude de $168 \mathrm{~m}$, no período de setembro a novembro de 2006.

Para a produção de mudas de rúcula foram utilizados como tratamentos: $\mathrm{T}_{1}=$ plantmax $^{\circledR}($ tratamento padrão $), \mathrm{T}_{2}=$ composto orgânico + casca de coco maduro triturada $(1: 1 \mathrm{v} /$ v), $\mathrm{T}_{3}=$ composto orgânico + cama de aviário + casca-dearroz carbonizada $(1: 1: 1 \mathrm{v} / \mathrm{v}), \mathrm{T}_{4}=$ composto orgânico + esterco bovino + casca-de-arroz carbonizada $(1: 1: 1 \mathrm{v} / \mathrm{v}), \mathrm{T}_{5}=$ composto orgânico + coprólitos de minhoca + casca-de-arroz carbonizada $(1: 1: 1 \mathrm{v} / \mathrm{v}), \mathrm{T}_{6}=$ composto orgânico + coprólitos de minhoca + caroço de açaí triturado $(1: 1: 1 \mathrm{v} / \mathrm{v}), \mathrm{T}_{7}=$ composto orgânico + coprólitos de minhoca + casca de coco triturada (1:1:1 v/v), $\mathrm{T}_{8}=$ composto orgânico + esterco bovino + casca de coco triturada $(1: 1: 1 \mathrm{v} / \mathrm{v}) .10 \%$ de carvão vegetal triturado, $1,0 \mathrm{~kg} \mathrm{~m}^{-}$ ${ }^{3}$ de calcário e $1,5 \mathrm{~kg} \mathrm{~m}^{-3}$ de termofosfato, exceto no tratamento $\mathrm{T}_{1}$. Foram acrescidos, $10 \%$ de carvão vegetal triturado, 1,0 kg. $\mathrm{m}^{-3}$ de calcário dolomitico e $1,5 \mathrm{~kg} . \mathrm{m}^{-3}$ de termofosfato, exceto no tratamento $\mathrm{T}_{1}$.

A eficiência do uso do substrato Plantmax ${ }^{\mathrm{o}}$ na produção de mudas olerícolas, tem sido comprovada em diversos trabalhos (Smiderle et al., 2001; Laviola et al., 2005), razão pela qual, neste trabalho, constitui-se no tratamento considerado padrão, em relação ao qual os demais tratamentos avaliados, tiveram suas eficiências comparadas.

As análises físicas e químicas dos constituintes que compõem cada tratamento foram realizadas no Instituto Campineiro de Análise de Solo e Água - ICASA, cujos resultados são apresentados nas Tabelas 1 e 2.

Os diferentes substratos secos foram vertidos sobre as bandejas, bem umedecidas, de poliestireno expandido, com 128 células, as quais foram inicialmente bem umedecida usando uma rs,com 128 células,ratos sobre de digest. No centro de cada célula foram colocadas três sementes de Rúcula, cv. cultivada na profundidade de $0,5 \mathrm{~cm}$. O desbaste foi realizado oito dias após a semeadura, deixando-se uma 
plântula por célula. As plântulas foram mantidas em condições de casa-de-vegetação (temperatura de $29,2{ }^{\circ} \mathrm{C} \pm$ $8{ }^{\circ} \mathrm{C}$ e umidade relativa do ar de $81,2 \% \pm 14,3 \%$ ), e submetidas à irrigação manual, diária, com início logo após a semeadura, aplicando $6 \mathrm{~mm}$ de lâmina de água ou $6 \mathrm{~L} \mathrm{~m}^{-2}$ de bandeja. Não foi feito controle da água lixiviada.

Aos 26 dias após a semeadura foram avaliadas: massa fresca da parte aérea (MFPA), a massa seca da raiz (MSRZ) e da parte aérea (MSPA) e a massa seca total da planta (MST). As massas da matéria seca da parte aérea e da raiz foram obtidas após a secagem do material em estufa de circulação forçada de ar a $60^{\circ} \mathrm{C}$, por 48 horas.

$\mathrm{O}$ delineamento experimental foi inteiramente casualizado, com três repetições, sendo a unidade experimental constituída por quatro plantas úteis. Utilizaram-se bandejas de poliestireno como unidades experimentais, sendo que meia bandeja era utilizada com a repetição de cada tratamento, composto por 64 células,

Tabela 1 - Composição química dos substratos considerados como tratamentos. Rio Branco,AC, UFAC, 2006.

\begin{tabular}{|c|c|c|c|c|c|c|c|c|c|c|c|c|c|c|c|c|}
\hline \multirow{2}{*}{ Tratamentos } & \multirow{2}{*}{$\mathrm{pH}$} & $\mathrm{P}$ & $\mathrm{K}$ & $\mathrm{Ca}$ & $\mathrm{Mg}$ & S & $\mathrm{Al}$ & B & $\mathrm{Cu}$ & $\mathrm{Fe}$ & $\mathrm{Mn}$ & $\mathrm{Zn}$ & Co & Mo & $\mathrm{Cl}$ & $\mathrm{Na}$ \\
\hline & & \multicolumn{15}{|c|}{ 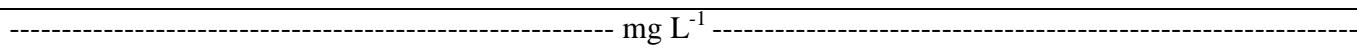 } \\
\hline $\mathrm{T}_{1}$ & 5,5 & 6,1 & 91,0 & 141,3 & $\begin{array}{c}118, \\
0\end{array}$ & $\begin{array}{c}119, \\
0\end{array}$ & 0,3 & 0,8 & - & 0,1 & 0,9 & 0,1 & - & - & 254,7 & 16 \\
\hline $\mathrm{T}_{2}$ & 7,7 & 15,5 & 206,0 & 18,9 & 12,9 & 9,4 & 0,5 & 0,3 & 0,1 & 0,4 & 0,1 & 0,1 & - & 0,1 & 467,7 & 60 \\
\hline $\mathrm{T}_{3}$ & 7,2 & 31,9 & 780,0 & 98,8 & 61,4 & 77,3 & 0,8 & 0,5 & 1,6 & 1,8 & 0,5 & 0,6 & - & 0,1 & 1049,62 & 240 \\
\hline $\mathrm{T}_{4}$ & 8,0 & 22,2 & 280,0 & 11,7 & 5,2 & 15,9 & 1,2 & 0,2 & 0,1 & 1,3 & 0,2 & 0,1 & - & 0,1 & 146,9 & 15 \\
\hline $\mathrm{T}_{5}$ & 7,4 & 9,1 & 58,0 & 17,2 & 12,3 & 6,2 & 3,2 & 0,1 & 0,1 & 1,5 & 0,2 & 0,02 & - & 0,1 & 8,3 & 9 \\
\hline $\mathrm{T}_{6}$ & 7,5 & 15,6 & 89,0 & 17,1 & 9,1 & 9,1 & 7,1 & 0,2 & 0,1 & 3,5 & 0,4 & 0,1 & - & - & 19,1 & 9 \\
\hline $\mathrm{T}_{7}$ & 7,4 & 8,7 & 87,0 & 20,1 & 12,1 & 5,9 & 2,6 & 0,2 & - & 1,3 & 0,2 & 0,1 & - & - & 178,6 & 28 \\
\hline $\mathrm{T}_{8}$ & 8,3 & 25,7 & 330,0 & 12,0 & 5,7 & 14,9 & 3,0 & 0,2 & 0,2 & 2,2 & 0,2 & 0,1 & - & 0,1 & 401,0 & 38 \\
\hline
\end{tabular}

T1 - Plantmax; T2 - Comp. orgânico + casca de coco triturado; T3 - Composto orgânico + cama de aviário + casca-de-arroz carbonizada; T4 - Composto orgânico + esterco bovino + casca-de-arroz carbonizada; T5 - Composto orgânico + coprólitos de minhoca + casca-dearroz carbonizada; T6 - Composto orgânico + coprólitos de minhoca + caroço de açaí triturado; T7 - Composto orgânico + coprólitos de minhoca + casca de coco triturada; T8 - Composto orgânico + esterco bovino + casca de coco triturado.

Tabela 2 - Características físicas dos substratos considerados como tratamentos. Rio Branco,AC, UFAC, 2006.

\begin{tabular}{|c|c|c|c|c|c|c|c|c|}
\hline \multirow[t]{2}{*}{ Tratamentos } & $\mathrm{Da}$ & Dp & EP & $\begin{array}{l}\text { Partículas } \\
\text { Sólidas }\end{array}$ & \multirow{2}{*}{$\begin{array}{c}\text { C.T.C. } \\
-\mathrm{mMol} \mathrm{cm}^{-3}--\end{array}$} & \multirow{2}{*}{$\begin{array}{c}\text { C.R.A. } \\
--\mathrm{m}^{3} \mathrm{~m}^{-3}-- \\
\end{array}$} & \multirow{2}{*}{ 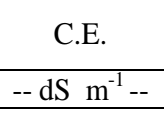 } & \multirow{2}{*}{$\begin{array}{c}\text { M.O. } \\
--{\mathrm{g} 100 \mathrm{~g}^{-1}-}^{-}\end{array}$} \\
\hline & ------ kg & $m^{-3}-----$ & --------- & (v/v) -------- & & & & \\
\hline $\mathrm{T}_{1}$ & 503,8 & 1767,4 & 57,8 & 24,2 & 795,0 & 0,70 & 1,656 & 70,37 \\
\hline $\mathrm{T}_{2}$ & 237,8 & 1894,6 & 88,9 & 11,1 & 560,0 & 0,52 & 0,797 & 56,18 \\
\hline $\mathrm{T}_{3}$ & 367,4 & 1857,7 & 82,0 & 18,0 & 690,0 & 0,54 & 3,050 & 60,10 \\
\hline $\mathrm{T}_{4}$ & 493,2 & 2015,6 & 78,2 & 21,8 & 505,0 & 0,64 & 1,002 & 55,56 \\
\hline $\mathrm{T}_{5}$ & 804,5 & 2161,7 & 65,0 & 35,0 & 305,0 & 0,51 & 0,492 & 31,83 \\
\hline $\mathrm{T}_{6}$ & 788,0 & 2207,2 & 66,7 & 33,3 & 322,5 & 0,55 & 0,425 & 28,27 \\
\hline $\mathrm{T}_{7}$ & 529,6 & 2198,9 & 76,8 & 23,2 & 287,5 & 0,36 & 0,583 & 28,90 \\
\hline $\mathrm{T}_{8}$ & 301,8 & 2005,8 & 86,2 & 13,8 & 445,0 & 0,53 & 0,903 & 45,26 \\
\hline
\end{tabular}

$\mathrm{Da}=$ densidade aparente; $\mathrm{Dp}=$ densidade das partículas; $\mathrm{EP}=$ espaço poroso; C.T.C. = capacidade de troca de cátions; C.R.A. = Capacidade de retenção de água; C.E. = condutividade elétrica.

T1 - Plantmax; T2 - Comp. orgânico + casca de coco triturado; T3 - Composto orgânico + cama de aviário + casca-de-arroz carbonizada; T4 - Composto orgânico + esterco bovino + casca-de-arroz carbonizada; T5 - Composto orgânico + coprólitos de minhoca + casca-dearroz carbonizada; T6 - Composto orgânico + coprólitos de minhoca + caroço de açaí triturado; T7 - Composto orgânico + coprólitos de minhoca + casca de coco triturada; T8 - Composto orgânico + esterco bovino + casca de coco triturado. 
das quais quatro foram utilizadas como parcela útil. As bandejas forma sorteadas nas bancadas, no interior da casa-de-vegetação, a uma altura de 1 metro do piso e a 3 metros da cobertura plástica. Os dados obtidos foram submetidos à análise de variância e as médias comparadas pelo teste Scoott Knot ao nível de 5\% de probabilidade.

\section{RESULTADOS E DISCUSSÃO}

Houve diferença significativa entre os substratos para todas as características analisadas (Tabela 3).

Conforme se pode observar na Tabela 3 , os tratamentos $\mathrm{T}_{4}, \mathrm{~T}_{5}$ e $\mathrm{T}_{7}$, foram os que apresentaram melhores resultados, não diferindo estatisticamente do tratamento padrão $\left(\mathrm{T}_{1}\right)$, quanto à produção de massa fresca da parte aérea, massa seca da parte aérea, da raiz e total.

No tratamento padrão $\left(\mathrm{T}_{1}\right)$, o valor de $\mathrm{pH}(5,5)$ interpretado como ótimo para substrato (Kämpf, 2000) e os nutrientes encontrados na solução do substrato (extração em água) revelam teores em $\mathrm{mg} \mathrm{L}^{-1}$ maiores de $\mathrm{Mg}(118,0)$, ótimos de $\mathrm{Ca}(141,3)$ e moderado de K (91) e P $(6,1)$ comparado aos teores ótimos recomendados por Plank (1989): 110 a $179 \mathrm{mg} \mathrm{L}^{-1}$ de K, 140 a $219 \mathrm{mg} \mathrm{L}^{-1}$ de Ca, 8 a 13 mg L ${ }^{-1}$ de P, 60 a $99 \mathrm{mg} \mathrm{L}^{-1}$ de $\mathrm{Mg}$ e 80 a $139 \mathrm{mg} \mathrm{L}^{-1}$ de $\mathrm{N}$.
Os substratos T4, T5 e T7, possuem ótimos teores de $\mathrm{P}$ e $\mathrm{K}$, mas baixos teores de $\mathrm{Ca}$ e $\mathrm{Mg}$, e também, possuem baixa condutividade elétrica $\left(0,49 \mathrm{dS} \mathrm{m}^{-1}\right.$ no T5 a $1,0 \mathrm{dS} \mathrm{m}^{-1}$ no T4).

A diferença na composição dos substratos entre T4 e T8 (ambos contêm composto e esterco bovino) e entre T5 e T7 (ambos contêm composto e coprólito de minhoca) é o material de enchimento, com casca-de-arroz carbonizada no $\mathrm{T} 4$ e T5 e casca de coco madura triturada no T7 e T8. A casca de arroz carbonizado e a casca de coco madura triturado possuem alta porosidade e aeração, porém a casca de coco torna o substrato menos denso, característica agravada pelo adubo orgânico, como esterco bovino no T8 e amenizado quando o adubo orgânico é coprólitos de minhoca, por ter natureza mais densa (Tabela 2).

Os substratos T3 e T8 possuem casca de coco madura triturada, um dos fatores desfavoráveis destes é a baixa densidade (Tabela 2), em razão da pouca quantidade de partículas sólidas, $11 \%$ e muito espaço de aeração, $74 \%$ (Figura 1), que pode ter causado baixa aderência às raízes, interferindo na absorção de nutrientes. Como espaço de aeração entende-se o volume de poros que se esvazia, logo após o substrato ter sido submetido à saturação hídrica,

Tabela 3 - Massa da matéria fresca da parte aérea e massa da matéria seca da parte aérea, raiz e total das mudas de rúcula em função dos diferentes tipos de substratos testados.

\begin{tabular}{|c|c|c|c|c|}
\hline \multirow{3}{*}{ Tratamentos } & \multirow{2}{*}{$\begin{array}{l}\text { Massa Fresca da } \\
\text { Parte Aérea } \\
\text { (MFPA) }\end{array}$} & \multicolumn{3}{|c|}{ Massa Seca } \\
\hline & & $\begin{array}{l}\text { Parte Aérea } \\
\text { (MSPA) }\end{array}$ & Raiz (MSRZ) & Total (MST) \\
\hline & -------- & -------- g -- & ---------- & ------ \\
\hline $\mathrm{T}_{1}-$ Plantmax ${ }^{\circledR}$ & $0,859 a^{*}$ & $0,117 \mathrm{a}$ & $0,033 \mathrm{a}$ & $0,150 \mathrm{a}$ \\
\hline $\mathrm{T}_{2}$ - Comp. orgânico + casca de coco triturado & $0,240 \mathrm{~b}$ & $0,032 b$ & $0,012 b$ & $0,044 \mathrm{~b}$ \\
\hline $\begin{array}{l}\mathrm{T}_{3} \text { - Composto orgânico + cama de aviário } \\
\text { + casca-de-arroz carbonizada }\end{array}$ & $0,170 \mathrm{~b}$ & $0,017 \mathrm{~b}$ & $0,004 b$ & $0,021 b$ \\
\hline $\begin{array}{c}\mathrm{T}_{4} \text { - Composto orgânico + esterco bovino } \\
\text { + casca-de-arroz carbonizada }\end{array}$ & $0,731^{\mathrm{a}}$ & $0,088 \mathrm{a}$ & $0,054 \mathrm{a}$ & $0,142 \mathrm{a}$ \\
\hline $\begin{array}{l}\mathrm{T}_{5}-\text { Composto orgânico }+ \text { coprólitos de } \\
\begin{array}{l}\text { minhoca } \\
\text { carbonizada }\end{array}\end{array}$ & $0,894^{\mathrm{a}}$ & $0,116 \mathrm{a}$ & $0,029 a$ & $0,145 \mathrm{a}$ \\
\hline $\begin{array}{c}\mathrm{T}_{6}-\text { Composto orgânico }+ \text { coprólitos de } \\
\text { minhoca }+ \text { caroço de açaí triturado }\end{array}$ & $0,134 b$ & $0,022 b$ & $0,006 b$ & $0,028 b$ \\
\hline $\begin{array}{c}\mathrm{T}_{7}-\text { Composto orgânico }+ \text { coprólitos de } \\
\text { minhoca }+ \text { casca de coco triturada }\end{array}$ & $0,544^{\mathrm{a}}$ & $0,067 \mathrm{a}$ & $0,041 \mathrm{a}$ & $0,107 \mathrm{a}$ \\
\hline $\begin{array}{l}\mathrm{T}_{8} \text { - Composto orgânico + esterco bovino } \\
\text { + casca de coco triturado }\end{array}$ & $0,271 b$ & $0,032 b$ & $0,007 \mathrm{~b}$ & $0,040 \mathrm{~b}$ \\
\hline Coeficiente de Variação (\%) & 20 & 20 & 18 & 17 \\
\hline
\end{tabular}

*Médias seguidas de letras distintas nas colunas, diferem estatisticamente entre si pelo teste Scott Knot $(\mathrm{p}<0,05)$. 


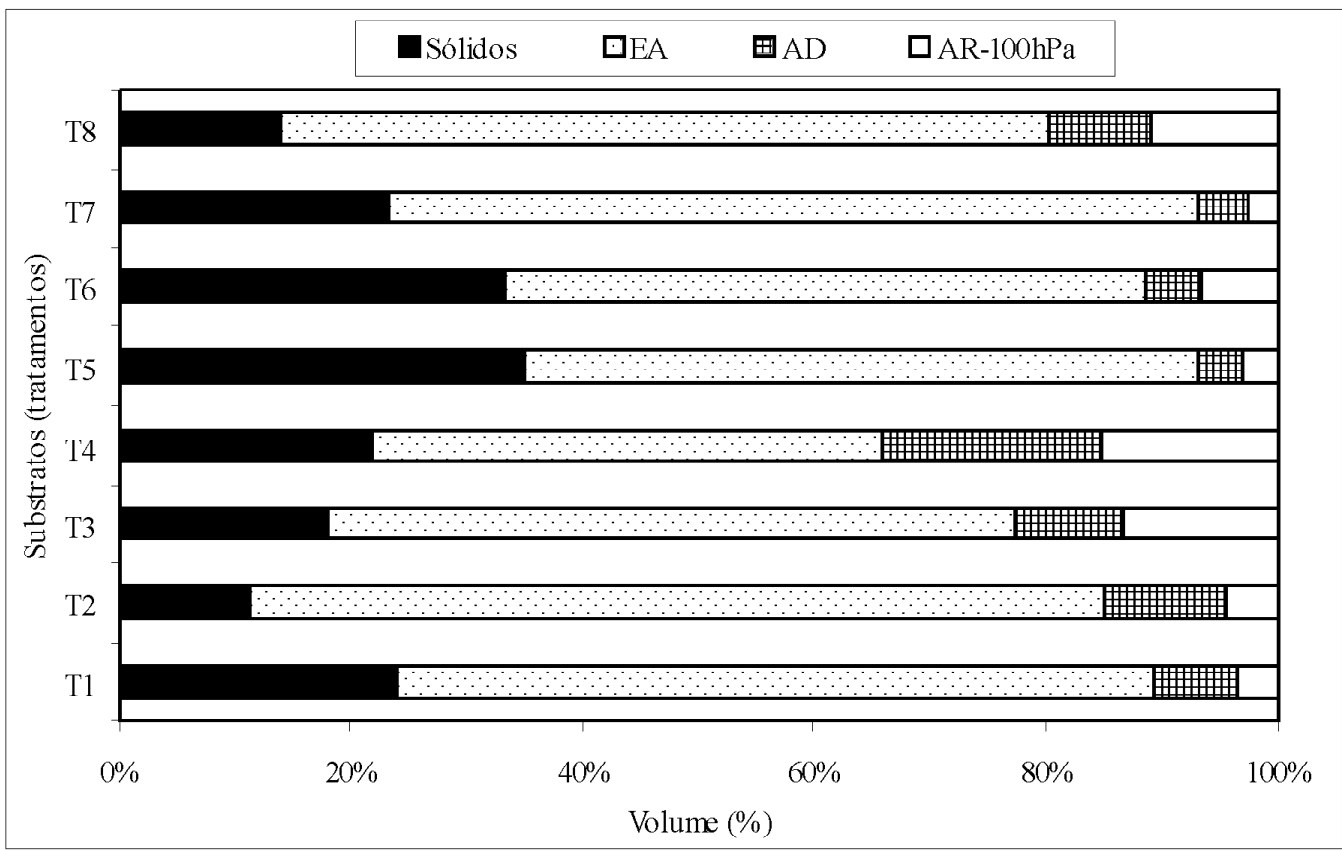

Figura 1 - Características físicas dos substratos analisados sob tensão de $50 \mathrm{~cm}$ de coluna de água. EA (espaço de aeração); AD (água disponível) AR-100 (Água remanescente a $100 \mathrm{hPa}$ ).

seguida por drenagem livre. O volume de água drenado corresponde ao volume de macroporos daquela amostra. Em geral, os valores de espaço de aeração deve variar entre 2 a $30 \%$ do volume, pois há plantas adaptadas para as diferentes faixas de macroporos no substrato (kämpf, 2000).

Em relação à água disponível (AD), Boodt \& Verdonck (1972) afirmam que os valores ideais variam de 0,20 a $0,40 \mathrm{~m}^{3} \mathrm{~m}^{-3}$ (Ferraz et al., 2005). Para esta propriedade física, todos os substratos apresentaram valores inferiores ao ideal indicado por Ferraz et al. (2005), variando de 0,026 $\mathrm{m}^{3} \mathrm{~m}^{-3} \mathrm{em} \mathrm{T7}$ a $0,19 \mathrm{~m}^{3} \mathrm{~m}^{-3} \mathrm{em}$ T4. Os substratos T5, T6 e T7, foram os que apresentaram menores quantidades de $\mathrm{AD}$, isso ocorreu pelo fato de em sua composição haver $33 \%$ de coprólitos de minhoca, que promoveu adensamento do substrato e diminuiu a AD

Trabalhos conduzidos por Souza et al. (2005), avaliando o efeito de coprólitos de minhocas como componente orgânico de substratos para a produção de mudas de couve-manteiga verificaram que tal constituinte apresenta maior benefício no crescimento das mudas quando a sua condição química é superior a do solo em fornecer nutrientes para as plantas.

Os tratamentos que contém coprólitos de minhoca na composição $\left(T_{5}, T_{6}\right.$ e $\left.T_{7}\right)$, em função dos demais componentes associados tiveram rendimentos de massa seca total diferenciados sendo o desempenho mais baixo observado no tratamento $\mathrm{T}_{6}$ em razão da presença do caroço de açaí triturado, que apesar de ser recomendado por Rogez (2000) como adubo orgânico, apresenta 81,29\% de fibra (hemicelulose, celulose e lignina) e apenas $5,97 \%$ de cinzas, características estas que dificultam o desenvolvimento do sistema radicular e deixam o substrato mais pobre em nutrientes, além de possui alto teor de ferro e alumínio (Tabela 1) justificando o menor rendimento observado no desenvolvimento das mudas (Tabela 3). Contudo, o coprólitos de minhoca associado ao composto orgânico nos demais tratamentos $\left(\mathrm{T}_{5} \mathrm{e} \mathrm{T}_{7}\right)$ foram capazes de superar os efeitos adversos advindos da utilização da casca de coco triturada e da casca de arroz carbonizada, garantindo um melhor desenvolvimento na produção de massa de matéria seca total destes tratamentos não diferindo estatisticamente do tratamento padrão $\left(\mathrm{T}_{1}\right)$.

A utilização de cama de aviário associada ao composto orgânico e casca de arroz carbonizada $\left(\mathrm{T}_{3}\right)$ constituiu-se no tratamento que apresentou menor rendimento de massa de matéria seca da parte aérea, raiz e total, justificados pelos teores muito mais elevados de $\mathrm{K} \mathrm{e}$ $\mathrm{P}$ respectivamente, cinco e três vezes acima do ótimo recomendado por Plank (1989). Além disso, apresentou os maiores valores de $\mathrm{Cl}$, $\mathrm{Na}$ e C.E. $\left(3,05 \mathrm{dS} . \mathrm{m}^{-1}\right)$. A C.E. deste 
substrato apresenta valor limitante para o crescimento da maioria das plantas, devendo esse valor situar-se abaixo de $1 \mathrm{dS} \mathrm{m}^{-1}$ para culturas sensíveis à salinidade (Ayers \& Westcot, 1991).

Assim, apenas $\mathrm{T}_{1}$ e $\mathrm{T}_{4}$ apresentam concentrações normais de salinidade, $\mathrm{T}_{3}$ possui concentração alta e os demais apresentaram concentrações baixas, característica que os tornam aptos a receber fertilização com sais.

A ausência de diferenças entre alguns tratamentos estudados, pode ser explicada pelos teores relativamente baixos de nutrientes mantidos na solução do substrato (disponibilidade imediata).

A elevada capacidade de troca de cátions (CTC) observada com destaque para os tratamentos $\left(\mathrm{T}_{1}, \mathrm{~T}_{2}\right.$ e $\left.\mathrm{T}_{3}\right)$, permitiu inferir que os nutrientes encontravam-se principalmente adsorvidos à fase sólida (matéria orgânica) e que, potencialmente, com o decorrer do tempo passaram à solução, refletindo assim, diretamente nos parâmetros avaliados (Tabela 1).

Nos substratos $\mathrm{T}_{5}$ e $\mathrm{T}_{7}$ (menores CTC) os nutrientes encontravam-se mais disponíveis na solução e, consequentemente, às plantas, o que explica em parte o bom desempenho desses tratamentos.

A capacidade de retenção de água (CRA) variou de 0,36 a $0,70 \mathrm{~m}^{3} \mathrm{~m}^{-3}$ (Tabela 2), inferior ao recomendado para substratos $\left(0,75\right.$ a $\left.0,90 \mathrm{~m}^{3} \mathrm{~m}^{-3}\right)$, citado por Ferraz et al. (2005). Esses valores são maiores para substratos, comparado a solos, por causa do maior conteúdo de água utilizado no cultivo de plantas em substratos (Ferraz et al., 2005).

\section{CONCLUSÃO}

A produção de mudas de rúcula com os substratos das formulações T4, T5 e T7, em cuja composição há além do composto orgânico, esterco bovino ou coprólitos de minhoca e como enximento, cascas-de-arroz carbonizada ou casca de coco madura triturada, equivalem em eficiência ao produto comercial Plantmax ${ }^{\circledR}$.

\section{REFERÊNCIAS BIBLIOGRÁFICAS}

AYERS, R.S.; WESTCOT, D.W. A qualidade da água de irrigação na agricultura. Campina Grande: UFPB, 1991. 218p. (FAO. Estudos de Irrigação e Drenagem, 29).

BOOT, M de.; HAYNES, R.J. The physical proprieties of the substrates in horticulture. Acta Horticulturae, Wagerningen, n.26, p.37-44, 1972.

\section{EMPRESA BRASILEIRA DE PESQUISA} AGROPECUÁRIA. Espécie rúcula ou pinchão. Disponível em: <wwww.cnph.embrapabr/bib/saibaquêl, rucula.htm>. Acesso em: 23 nov. 2006.
FERRAZ, M.V.; CANTURION, J.F.; BEUTLER, A.N. Caracterização física e química de alguns substratos comerciais. Acta Scientiarum Agronomy, Maringá, v.27, n.2, p.209-214, abr./jun. 2005.

FILGUEIRA, F.A.R. Novo manual de olericultura: agrotecnologia moderna na produção e comercialização de hortaliças. 2.ed. rev. e ampl. Viçosa, MG: UFV, 2003.

KÄMPF, A.N. Seleção de materiais para uso como substrato. In: KÄMPF, A.N.; FERMINO, M.H. (Eds.). Substrato para plantas: a base da produção vegetal em recipientes. Porto Alegre: Gênesis, 2000. p.139-145.

LAVIOLA, B.G.; LIMA, P.A.; WAGNER JÚNIOR, A.; MAURI, A.L.; VIANA, R.S.; LOPES, J.C. Efeito de diferentes substratos na germinação e no desenvolvimento inicial de jiloeiro (Solanum gilo Raddi), cultivar Verde Claro. Ciência e Agrotecnologia, Lavras, v.30, n.3, p.415-421, maio/jun. 2005.

\section{MOREIRA, D.F. Uso de coprólitos de minhoca como componente de substrato para produção orgânica de mudas de mamão. Rio Branco: Universidade Federal do Acre, 2005. 22 p.}

PLANK, C. O. Soil test handbook for Georgia. Athens, university of Georgia, 1989. 316p.

ROGEZ, H. Açaí: preparo, composição e melhoramento da conservação. Belém: EDUFPA, 2000. 313p.

ROSAS, M. de F.; BEZERRA, F.C.; CORREIA, D.; SANTOS, F.J. de S.; ABREU, F.A.P. de; FURTADO, A.A.L.; BRÍGIDO, A.K.L.; NORÕES, E.R. de V. Utilização da casca de coco como substrato agrícola. Fortaleza: Embrapa, 2002. (Documentos, 52).

SILVA, R.P. da; PEIXOTO, J.R.; JUNQUEIRA, N.T.V. Influência de diversos substratos no desenvolvimento de mudas de maracujazeiro azedo (Passiflora edulis Sims f. flavicarpa DEG). Revista Brasileira de Fruticultura, Jaboticabal, v.23, n.2, p.377-381, 2001.

SMIDERLE, O.J.; SALIBE, A.B.; HAYASHI, A.H.; MINAMI, K. Produção de mudas de alface, pepino e pimentão em substrato combinando areia, solo e Plantmax. Horticultura Brasileira, Brasília, v.19, n.3, p.253-257, 2001.

SOUZA, S. da S.; ARAÚJO NETO, S.E. de; FERREIRA, R.L.F.; KUSDRA, J.F. Produção orgânica de mudas de couvemanteiga em substratos a base de coprólito de minhocas. In: SEMINÁRIO DE INICIAÇÃO CIENTÍFICA, 14., 2005, Rio Branco. Anais... Rio Branco: UFAC, 2005. CD-ROM. 